Research Article

\title{
Predicting the Performance of Rural Banks in Ghana Using Machine Learning Approach
}

\author{
Emmanuel Awoin (D), Peter Appiahene (iD, Frank Gyasi, and Abdulai Sabtiwu \\ University of Energy and Natural Resources, Sunyani, Ghana \\ Correspondence should be addressed to Emmanuel Awoin; emmanuelawoinpass@gmail.com
}

Received 2 September 2019; Revised 4 January 2020; Accepted 13 January 2020; Published 19 February 2020

Academic Editor: Antonin Dvorák

Copyright (c) 2020 Emmanuel Awoin et al. This is an open access article distributed under the Creative Commons Attribution License, which permits unrestricted use, distribution, and reproduction in any medium, provided the original work is properly cited.

\begin{abstract}
The idea of rural banks was introduced as a result of limited commercial bank branches in rural areas to mobilize their resources for rural development. It is also believed that financial institutions such as rural banks are powerful tools for mitigating poverty. Nevertheless, some of these banks are rather increasing the burden of people through illegal activities and mismanagement of resources. Assessing banks' performance using a set of financial ratios has been an interesting and challenging problem for many researchers and practitioners. Identification of factors that can accurately predict a firm's performance is of great interest to any decision-maker. The study used ARB's financial ratios as its independent variables to assess the performance of rural banks and later used random forest algorithm to identify the variables with the most relevance to the model. A dataset was obtained from the various banks. This study used three decision tree algorithms, namely, C5.0, C4.5, and CART, to build the various decision tree predictive models. The result of the study suggested that the C5.0 algorithm gave an accuracy of 100\%, followed by the CART algorithm with an accuracy of $84.6 \%$ and, finally, the C4.5 algorithm with an accuracy of 83.34 on average. The study, therefore, recommended the usage of the C5.0 predictive model in predicting the financial performance of rural banks in Ghana.
\end{abstract}

\section{Introduction}

In order to fast track the development of rural areas in Ghana, rural banks were introduced. The Association of Rural Banks (ARB) described some of the roles of rural banks as follows: cultivating the habits of savings among rural inhabitants, mobilizing resources locked up in the rural areas into the banking systems to facilitate development, and identifying viable industries in their respective areas for investment and development [1]. It is believed that financial institutions are powerful tools to mitigate poverty [2], but some of them are rather increasing the burden of people through illegal activities and mismanagement of resources [3]. The collapse of most of these institutions can be seen as a result of them not being able to evaluate and predict their financial standings in the years ahead [4]. Therefore, the main objective of this project is to develop and propose a predictive model capable of predicting the financial standing of financial institutions as well as identifying the most influencing financial ratios, using rural banks in Ghana as a case study area and decision tree algorithms (C5.0, C4.5, and CART).

The remainder of this paper is organized as follows: the next section (Section 2) provides a literature review; Section 3 presents the methodology developed and followed in this study and documents its findings; Section 4 summarizes and concludes the paper.

\section{Review of the Literature}

It is self-evident and based on empirical observation that most financial institutions in Ghana over the years have failed in their operations because they were unable to predict their financial status with respect to their progress or failure. An institution like Diamond Microfinance Limited (DKM) company, which started its operations in 2005, had its operations suspended by the Central Bank of Ghana after it violated the banking Act. Upon the analyses made by Citi 
Business News, the company failed to hold sufficient assets to meet its liabilities to depositors [5]. Other financial institutions that have suffered a similar collapse are UT Bank and Capital Bank. In August 2017, the bank of Ghana revoked their license describing them as "deeply insolvent" [4]. Because of these cases, many people feel reluctant to invest in some of these financial institutions. A lot of studies have been made to reduce this issue through predictive models using decision tree algorithms and the financial ratios of these institutions.

According to [6], the financial ratios have proven to be the most accurate method for analyzing financial reports which have a high accuracy to treat the points of weakness, effectively and efficiently. Using financial ratios to evaluate a firm's performance is not an emerging field of study, but rather this has been in the system for quite a long time. Financial ratios derived from financial statements can be used to predict stock price trends in emerging markets [7]. A simple literature search can find literally thousands of publications on topics related to financial ratios. The underlying studies often differentiate themselves from the rest by developing and using different independent variables (financial ratios) and/or employing different statistical or machine learning-based analysis techniques such as decision tree, neutral network, to mention but a few [8].

Machine learning is a subfield of computer science that evolved from the study of pattern recognition and computational learning theory in artificial intelligence [9]. Machine learning makes use of the construction of algorithms that can learn from and make predictions from data [10]. A research conducted by [11] indicated that recent years have seen a boost in using a predictive classification in medical diagnosis to perform research in this field, and the majority of these papers focus their goal on improving accuracy. Their results, using age, weight, waist, hip, and height as indicators, explained that after a successful experiment with four different machine learning algorithms to make the predictions on type II diabetes, ID3 had an accuracy of 78.57, Naïve Bayes had 79.89, AdaBoost had 84.19, and random forest had the highest accuracy of $85 \%$.

Authors of [12], in their paper, sought to address the difference between deep neural network- (DNN-) based computer vision and human vision with respect to image production/capturing. It indicated that it is easy to produce images that are completely unrecognizable to humans, but that state-of-the-art DNNs believe to recognize objects with over 99\% confidence. Given the near-human ability of DNNs to classify visual objects, questions arise as to what differences remain between computer and human vision. A study conducted by [13] revealed a major difference between DNN and human vision. Changing an image, originally correctly classified (e.g., as a lion), in a way imperceptible to human eyes, can cause a DNN to label the image as something else entirely.

Moreover, [14] used multiple regression to evaluate the performance of students using English, Mathematics, Chemistry, and Physics to predict their grade point average. They used performance measures such as Root Mean Square
Error in measuring their model's efficiency. At the end of their analysis, they had a Root Mean Square Error of 0.342 . Another AI research work performed by [15] used financial ratios together with the various popular machine learning algorithms to predict the bankruptcy possibility of some companies in China. After the analysis of their results, random forest and decision tree had the most accuracy, that is, $95 \%$ and $94 \%$, respectively.

The prediction of corporate bankruptcies is an important and widely studied topic since it can have a significant impact on bank lending decisions and profitability. Atiya [16], performed an empirical experiment with a total of 37 ratios which is composed of financial and other nonfinancial ratios and used principle component analysis (PCA) to extract suitable variables. The decision tree (DT) classification methods (C5.0, CART, and CHAID) and logistic regression (LR) techniques were used to implement the financial distress prediction model. Finally, the experiments acquired a satisfying result, which testifies to the possibility and validity of their proposed methods for the financial distress prediction of listed companies that were used as test subjects. Ocal et al. [17] used C5.0 and CHAID decision tree algorithms to estimate the financial failure and/or success of a given manufacturing company, and 35 financial ratios were used as independent variables calculated on the grounds of both company's annual financial statements and notes from 2007 to 2013. According to the results, the model's classification accuracy was $90.97 \%$ for the training set and $87.5 \%$ for the testing set. Thus, the classifications made by the C5.0 algorithm can be considered successful. Kim and Kang [18] tried to strengthen the predictive accuracy by combining ensemble with neural networks, but other studies have made it obvious that decision trees combined with financial ratios analysis might predict the financial distress of companies more accurately (Kim and Kang, 2010).

Apart from the use of decision tree in making predictions, one interesting technique in the event of prediction is neural networks [19]. But this research paper will restrict itself to the use of the decision tree algorithm as the decision tree algorithm is one of the most important classification measures in data mining [20].

\section{Methodology}

The main purpose of this project is to develop a predictive framework capable of classifying rural banks' financial status in Ghana. This could not have been accomplished without the necessary steps of data acquisition, data preprocessing, feature selection, and classification. An overview of the framework is shown in Figure 1.

3.1. Study Area. This study used rural banks in Ghana that are registered under the Association of Rural Banks in Ghana as its case study. According to the Bank of Ghana, as of August 2018, the number of rural banks that are legally known is one hundred and forty-five (145) [1]. This research project used the financial ratings of rural banks in Ghana as 


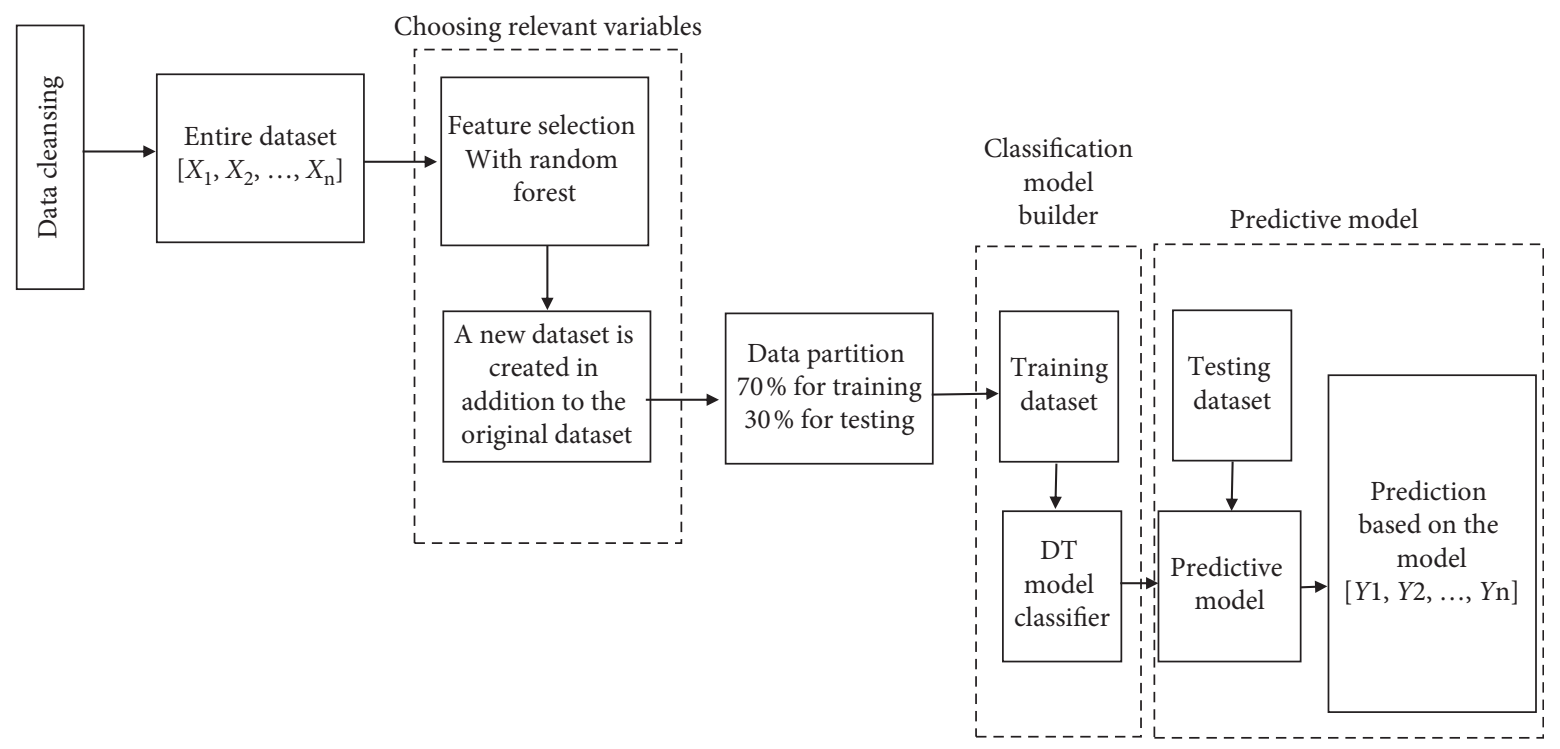

FIGURe 1: Proposed DT model for classifying rural banks' financial status.

collated by the ARB Apex Bank for the performance of rural banks in the various quarters.

3.2. Data Collection. The data were collected from the ARB Apex Bank, Sunyani branch, and it was within the following quarters.

(i) The second quarter ended in June 2014.

(ii) The fourth quarter ended December 2014.

(iii) The fourth quarter ended in December 2015.

(iv) The third quarter ended in September 2017.

(v) The second quarter ended in June 2018.

3.3. Dependent Variable. Our dependent variable is the status of the financial institution's end of the financial period quarter as to whether it was strong, satisfactory, fair, marginal, or unsatisfactory. If a financial period is marked as strong, satisfactory, fair, marginal, or unsatisfactory, it will continue to remain so until the next financial period proves otherwise. At the end of the preprocessing process, we were left with six hundred and fifty-seven (657) Data Manipulation Units (DMUs), with ninety-nine (99) being strong, three hundred and thirty (330) being satisfactory, one hundred sixty-four (164) being fair, and sixty-four (64) being marginal. Table 1 shows the rating range and interpretation of each financial status.

3.4. Independent Variables. The independent variables or predictors used in the research are the various financial ratios or parameters that are being used by the ARB Apex Bank to assess the performance of their member rural banks. They are in four broad categories, namely, capital, asset including asset quality and asset utilization, earnings/profitability, and liquidity. The broad themes have been detailed into sixteen (16) parameters for the assessment in Table 2.
3.5. Adopted Decision Tree Algorithms. C5.0 was developed by Ross Quinlan in 1994. It works by splitting the sample based on the field that provides the maximum information gain. Each subsample defined by the first split is then split again, usually based on a different field. And the process repeats until the subsamples cannot be split any further. The process repeats until the subsamples cannot be split any further. C5.0 R package version 0.1.2 was developed by Max et al. [21].

$$
\begin{aligned}
H(T) & =I_{E}(p 1, p 2, \ldots, p j)=-\sum_{i=1}^{J} p i \log _{2} p i \\
\overbrace{\overparen{I G(T, a)}}^{\text {information gain }} & =\overbrace{H(T)}^{\text {entropy (parent) }}-\overbrace{H(T \mid a)}^{\text {weighted sum of entropy (children) }} \\
& =-\sum_{i=1}^{J} p i \log _{2} p i-\sum_{a} p(a) \sum_{i=1}^{J}-\operatorname{Pr}(i \mid a) \log _{2} \operatorname{Pr}(i \mid a) .
\end{aligned}
$$

3.6. Classification and Regression Tree (CART). The Classification and Regression Tree was developed by Breiman et al. [22]. It is a binary decision tree, constructed by splitting the node into two child nodes repeatedly. Classification and Regression Tree (CART) algorithm is a classification algorithm for building a decision tree based on Gini's impurity index as a splitting criterion. CART is a binary tree built by splitting a node into two child nodes repeatedly. It uses the $\mathrm{R}$ package "rpart" version 4.1-13, developed by Therneau et al. [23].

$$
\begin{aligned}
\mathrm{IG}(p) & =\sum_{i=1}^{J} p i \sum_{k \neq i}^{J} p k=\sum_{i=1}^{J} p i=(1-p i)=\sum_{i=1}^{J}\left(p i-p i^{2}\right) \\
& =\sum_{i=1}^{J} p i-\sum_{i=1}^{J} p i^{2}=1-\sum_{i=2}^{J} p i^{2} .
\end{aligned}
$$


TABLE 1: Various classes used by ARB to classify rural banks' financial status (source: Association of Rural Banks Quarter Report, 2017).

\begin{tabular}{|c|c|c|c|}
\hline $\begin{array}{l}\text { Rating } \\
\text { range }\end{array}$ & Rating analysis & Interpretation of rating analysis & DMUs \\
\hline $1.0-1.50$ & Strong & Sound in all indicators, no supervisory response required & 99 \\
\hline $1.50-2.50$ & Satisfactory & $\begin{array}{c}\text { Fundamentally sound with modest correctable weaknesses; supervisory } \\
\text { responses limited }\end{array}$ & 330 \\
\hline $2.50-3.50$ & Fair (watch category) & $\begin{array}{c}\text { Combination of weaknesses which if not addressed will become severe. Watch } \\
\text { category }\end{array}$ & 164 \\
\hline $3.50-4.50$ & Marginal (signs of risk of failure) & $\begin{array}{c}\text { Immoderate weaknesses: unless properly addressed, could impair future } \\
\text { viability. Needs close supervision. }\end{array}$ & 64 \\
\hline $4.50-5.0$ & $\begin{array}{l}\text { Unsatisfactory (high degree of } \\
\text { failure evident) }\end{array}$ & High risk of failure in the near term. Needs constant supervision. & 0 \\
\hline
\end{tabular}

TABLE 2: Independent variables used by ARB (source: Association of Rural Banks Quarter Report, 2017).

\begin{tabular}{|c|c|c|c|}
\hline \multicolumn{4}{|c|}{ Independent variables } \\
\hline Paid-up capital & Loss/NPL ratio & Other assets to total assets ratio & Return on earning assets \\
\hline $\begin{array}{l}\text { Capital adequacy ratio } \\
\text { (CAR) }\end{array}$ & $\begin{array}{l}\text { Earning assets to total } \\
\text { assets ratio }\end{array}$ & $\begin{array}{l}\text { Property, plant, and equipment to total } \\
\text { assets ratio }\end{array}$ & Costs to income ratio \\
\hline Past due ratio & $\begin{array}{l}\text { Liquid assets to total assets } \\
\text { ratio }\end{array}$ & Return on assets (ROA) & $\begin{array}{c}\text { Average primary reserve ratio for the } \\
\text { quarter }\end{array}$ \\
\hline $\begin{array}{l}\text { Nonperforming loans (NPL) } \\
\text { ratio }\end{array}$ & $\begin{array}{l}\text { Advances to loanable } \\
\text { funds ratio }\end{array}$ & Return on equity (ROE) & $\begin{array}{c}\text { Average secondary reserve ratio for } \\
\text { the quarter }\end{array}$ \\
\hline
\end{tabular}

C4.5 builds decision trees from a set of training data and the training data is a set $S=s 1, s 2, \ldots$ of already classified samples. The attribute with the highest normalized information gain is chosen to make the decision. C4.5 goes back through the tree once it is created and attempts to remove the branches that do not help by replacing them with leaf nodes. It uses the RWeka package, version 0.4-39, developed by Hornik et al. [24], and contains the J48 function for executing C4.5 models.

3.7. Selecting the Most Important Variables with the Random Forest Algorithm. Random forest algorithm is very popular for feature selection in data science because of its tree-based strategy that is naturally ranked by how good they add up to the purity of the nodes. Nodes that contribute greatly to the purity of the tree are known or seen as the most important ones. Reference [25] proposed a technique for feature selection using the mean decrease accuracy (MDA) and mean decrease gini (MDG) in random forest. This technique scores the MDA and MDG of variables, sum up the scores, rank the total scores of the variables in decreasing order, and runs the random forest algorithm again with the top 50\% variables.

In this paper, we used a similar technique like the one proposed by [25]. We focused on the MDG and set our threshold to 0.10; that is, all the variables that gave MDG less than 0.10 were eliminated and considered less relevant. After identifying the most relevant variables, a new dataset was created for comparative purposes.

3.8. The Proposed Model. The proposed DT model for classifying rural banks' financial status is shown in Figure 1 .

\subsection{Discussions and Findings}

(i) Initially, all sixteen (16) predictors were used to build the random rorest model, and upon the summary of the model, it was observed that thirteen (13) of the predictors (i.e., the predictors with asterisks $\left({ }^{*}\right)$ in Table 3 ) had an MDG greater than or equal to 0.10 , making them the most relevant for the model, whereas the other three were indicated to be less relevant.

(ii) The model with all the predictors came out with an error rate of $10.1 \%$ and an execution time of 2.11 seconds, whilst the model with the thirteen predictors came out with an error rate of $11.05 \%$ and an execution time of 1.75 seconds.

(iii) Upon building the C5.0 models using both the dataset with all the predictors and the one with the eleven predictors, the models came out with the same results. This can be seen in Figure 2 as they both yielded the same confusion matrix and statistics. The models showed a $100 \%$ accuracy and also showed a $100 \%$ accuracy when the test data was used for prediction (i.e., all 53 banks with fair status, all 14 banks with marginal status, all 97 banks with satisfactory status, and all 34 banks with strong status). The confusion matrix can be found in the following.

(iv) Upon building the C4.5 model with the training dataset containing all the predictors, the model came out with a $94.12 \%$ accuracy and also showed $82.83 \%$ when the test data was used for prediction (i.e., only 39 out of 53 banks with fair status, only 10 out of 14 banks with marginal status, only 89 out of 97 banks with satisfactory status, and only 26 out 


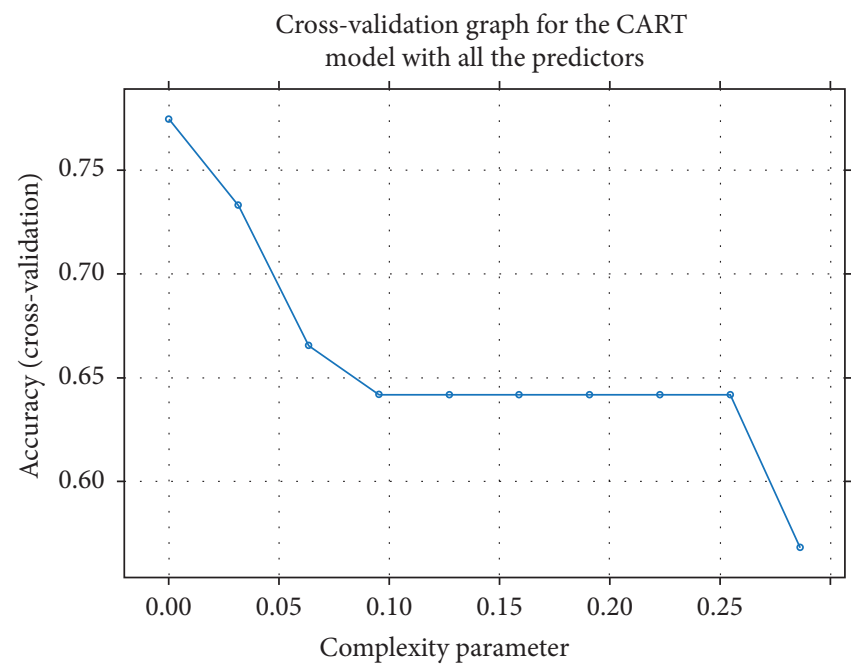

(a)

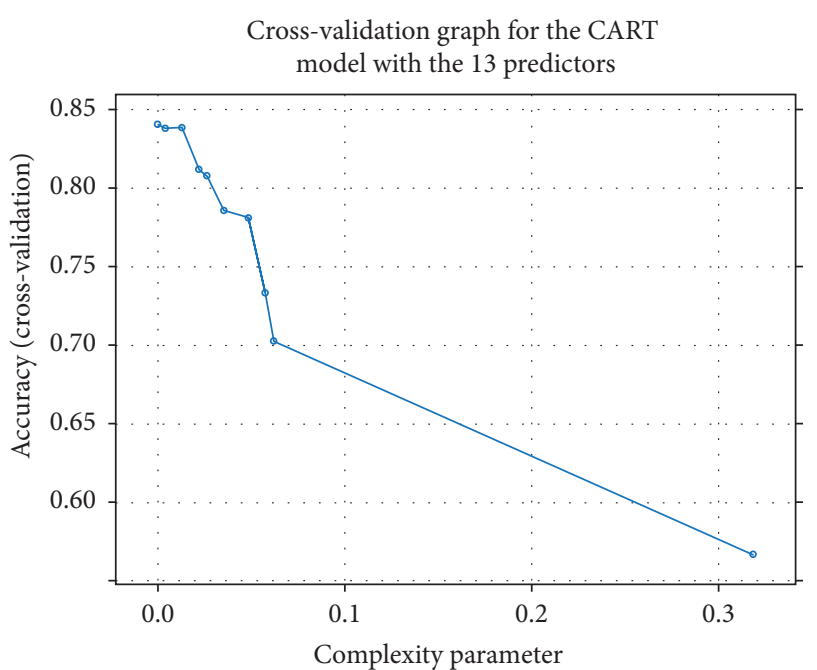

(b)

Figure 2: Cross-validation graph for the CART models.

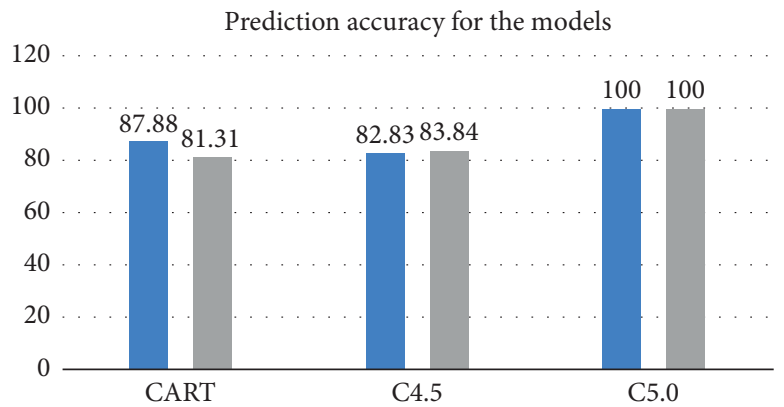

Accuracy for the models with all predictors

Accuracy for the models with thirteen predictors

FIgURE 3: Graphical representation of the models accuracies.

TABLe 3: Relevant $\left({ }^{*}\right)$ and less relevant variables after building the MLR model.

\begin{tabular}{|c|c|c|c|}
\hline \multicolumn{4}{|c|}{ Independent variables } \\
\hline Paid-up capital & Loss/NPL ratio* & Other assets to total assets ratio* & Return on earning assets* \\
\hline $\begin{array}{l}\text { Capital adequacy ratio } \\
(\mathrm{CAR})^{*}\end{array}$ & $\begin{array}{l}\text { Earning assets to total } \\
\text { assets ratio* }\end{array}$ & $\begin{array}{c}\text { Property, plant, and equipment to total } \\
\text { assets ratio* }\end{array}$ & Costs to income ratio* \\
\hline Past due ratio* & $\begin{array}{c}\text { Liquid assets to total assets } \\
\text { ratio* }\end{array}$ & Return on assets $(\mathrm{ROA})^{*}$ & $\begin{array}{c}\text { Average primary reserve ratio for the } \\
\text { quarter }\end{array}$ \\
\hline $\begin{array}{l}\text { Nonperforming loans (NPL) } \\
\text { ratio* }\end{array}$ & $\begin{array}{l}\text { Advances to loanable funds } \\
\text { ratio }\end{array}$ & Return on equity (ROE)* & $\begin{array}{c}\text { Average secondary reserve ratio for } \\
\text { the quarter* }\end{array}$ \\
\hline
\end{tabular}

TABLE 4: Statistical information on the various adapted DT algorithms.

\begin{tabular}{lccccc}
\hline & Decision tree algorithm & Accuracy & $P$ value & Kappa & No information rate \\
\hline \multirow{3}{*}{ Dataset with all initial predictors } & C5.0 & 1 & $2.2 e-16$ & 1 & 0.4899 \\
& C4.5 & 0.9412 & $2.2 e-16$ & 0.9094 & 0.5076 \\
\hline \multirow{3}{*}{ Dataset with the 13 predictors } & CART & 0.8787 & $2.2 e-16$ & 0.8078 & 0.4949 \\
& C5.0 & 1 & $2.2 e-16$ & 1 & 0.4646 \\
& CART & 0.9387 & $2.2 e-16$ & 0.9038 & 0.4646 \\
\hline
\end{tabular}


of 34 banks with strong status were predicted correctly). Using 10-fold cross validation, the model gave a Kappa value of 0.6908 . More details about the C4.5 models with all sixteen predictors can be seen in Table 3 .

(v) Upon building the C4.5 model with the training dataset, containing the 13 predictors, the model came out with a $93.87 \%$ accuracy and also showed an $83.84 \%$ accuracy when the test data was used for prediction (i.e., only 40 out of 53 banks with fair status, only 12 out of 14 banks with marginal status, only 81 out of 97 banks with satisfactory status, and only 33 out of 34 banks with strong status were predicted correctly). More details about the C4.5 models with the eleven predictors can be seen in Table 3.

(vi) Upon building the CART model with the training dataset containing all the predictors, the model came out with an $87.87 \%$ accuracy and also showed $87.88 \%$ when the test data was used for prediction (i.e., only 46 out of 58 banks with fair status, only 15 out of 18 banks with marginal status, only 94 out of 98 banks with satisfactory status, and only 19 out of 24 banks with strong status were predicted correctly). More details about this model can be seen in Table 3. Cross-validating this model, the CV model gave the best $\mathrm{CP}$ of 0 but came out with an accuracy less than the initial CP of 0.01 (this can be seen from the graph at the left side of Figure 2), so the final model was based on the default CP.

(vii) Upon building the CART model with the training dataset containing the eleven predictors, the model came out with an $81.31 \%$ accuracy when the test data was used for prediction (i.e., only 37 out of 58 banks with fair status, only 19 out of 18 banks with marginal status, only 91 out of 98 banks with satisfactory status, and only 14 out of 24 banks with strong status were predicted correctly). Cross-validating this model, the CV model gave the best $\mathrm{CP}$ of 0 but came out with an accuracy less than the initial CP of 0.01 (this can be seen from the graph at the right side of Figure 2), so the final model was based on the default CP.

(viii) The random forest model with all the initial predictors had an error rate negligently less than that of the one with the thirteen predictors. However, the second model attained a much better execution time as a result of the trade-off. Moreover, with the most relevant financial ratios unravelled by the random forest model, rural banks in Ghana can focus more on getting better results on those ratios so as to attain a better financial standing.

(ix) Figure 3 is a chart showing the accuracies obtained from all the models.

\section{Conclusion and Recommendation}

4.1. Conclusion. Laconically, machine learning algorithms are making things easier as they learn from precedence and forecast future events. There are numerous machine learning algorithms, but the one which is very easy to savvy by most people, particularly, mathematically inclined people, is the decision tree due to its easy-to-understand graphical representation. This study used DT algorithms in building a model that can forecast the financial status of a financial institution. Our study also aimed to identify the financial ratios that have the most impact in evaluating the performance of these financial institutions using random forest variable selection methodology of which 13 out of the 16 predictors emerged as most relevant to the model. Our models showed high accuracy using our dataset. This depicts that the DT algorithms can give precise forecasting when it comes to financial institution's failure. The C5.0 algorithm had the highest accuracy among the three algorithms we used, followed by the CART algorithm and, last but not least, the C4.5 on average. Other statistical information on the various DT models can be seen in Table 4. Other statistical information on the various DT models can be seen in Table 4 .

4.2. Recommendations. For future directions, we aim at increasing the dataset to an amount greater than what was used in this project, as it can help improve the accuracies more than what was obtained in this project. Also, commercial banks' financial data can be used instead of using rural banks' financial data, provided they conform with the independent variables used in building the model. Furthermore, in the future, we would like to combine traditional machine learning to deep learning in order to efficiently tackle rural banks' bankruptcy in Ghana.

\section{Data Availability}

The institution that provided us with data made it clear that it is restricted and should not be shared.

\section{Conflicts of Interest}

The authors declare that they have no conflicts of interest.

\section{References}

[1] Rural Banks, 2018, http://bog.gov.gh.

[2] P. Appiahene and Y. M. Missah, "Predicting the operational efficiency of banks in the presence of information technology investment," in Proceedings of the International Conference on Artificial Intelligence and Soft Computing (ICAISC), pp. 6-11, Academics World, Munich-Germany, 2019.

[3] I. Akuamoah Boateng and A. Agyei, "Microfinance in Ghana: development, success factors and challenges," International Journal of Academic Research in Accounting Finance and Management Sciences, vol. 3, no. 4, pp. 153-160, 2013.

[4] Akwa, S. N., UT, Capital Bank collapse: confidence in banking sector still strong-Ofori Atta, 2017, http://MyJoyOnline.com.

[5] BoG Shuts Down DKM Microfinance-Citifmonline.com, http://citifmonline.com/Ghana, 2015. 
[6] A.-R. K. El- Dalabeeh, "The role of financial analysis ratio in evaluating performance (case study: national chlorine industry)," Interdisciplinary Journal of Contemporary Research in Business, vol. 5, no. 2, pp. 13-29, 2013.

[7] T. Arkan, "The importance of financial ratios in predicting stock price trends: a case study in emerging markets," Zeszyty Naukowe Uniwersytetu Szczecińskiego Finanse Rynki Finansowe Ubezpieczenia, vol. 1, no. 1, pp. 13-26, 2016.

[8] D. Delen, C. Kuzey, and A. Uyar, "Measuring firm performance using financial ratios: a decision tree approach," Expert Systems With Applications, vol. 40, no. 10, pp. 3970-3983, 2013.

[9] S. F. Deangelis, Artificial Intelligence: How Algorithms Make Systems Smart, WIRED, San Francisco, CA, USA, 2014.

[10] Expert System, What Is Machine Learning? A Definition-Expert System, 2017, https://www.expertsystem. com/machine-learning-definition/.

[11] W. Xu, J. Zhang, Q. Zhang, and X. Wei, "Risk prediction of type II diabetes based on random forest model," 2017.

[12] J. Yosinski, J. Clune, and A. Nguyen, "Deep neural networks are easily fooled: high confidence predictions for unrecognizable images," 2015, https://arxiv.org/abs/1412.1897.

[13] C. Szegedy, W. Zaremba, I. Sutskever et al., "Intriguing properties of neural networks," 2013, https://arxiv.org/abs/ 1312.6199 .

[14] E. Uchenna, C. Adeyeye, and R. Abiobaragha, "Multiple regression of students' performance using forward selection procedure," Backward Elimination and Stepwise Procedure, vol. 5, no. 12, pp. 226-232, 2016.

[15] Y. Li and Y. Wang, "Machine learning methods of bankruptcy prediction using accounting ratios," Open Journal of Business and Management, vol. 6, no. 1, pp. 1-20, 2018.

[16] A. F. Atiya, "Bankruptcy prediction for credit risk using neural networks: a survey and new results," IEEE Transactions on Neural Networks, vol. 12, no. 4, pp. 929-935, 2001.

[17] N. Ocal, M. K. Ercan, and E. Kadioglu, "Predicting financial failure using decision tree algorithms: an empirical test on the manufacturing industry at Borsa Istanbul," International Journal of Economics and Finance, vol. 7, no. 7, pp. 189-206, 2015.

[18] M. J. Kim and D. K. Kang, "Ensemble with neural networks for bankruptcy prediction," Expert Systems with Applications, vol. 37, no. 4, pp. 3373-3379, 2010.

[19] M. D. Odom and R. Sharda, "A neural network model for bankruptcy prediction," in Proceedings of the 1990 IJCNN International Joint Conference on Neural Networks, vol. 2, pp. 163-168, IEEE, San Diego, CA, USA, 1990.

[20] Q.-y. Dai, C.-p. Zhang, and H. Wu, "Research of decision tree classification algorithm in data mining," International Journal of Database Theory and Application, vol. 9, no. 5, pp. 1-8, 2016.

[21] A. Max, S. Weston, and M. Culp, "Package C50," in Multiple Regression Analysis: Use Adjusted R-Squared and Predicted RSquared to Include the Correct Number of Variables, Minitab Blog Editor, 2018, http://blog.minitab.com/blog/adventures-instatistics-2/multiple-regession-analysis-use-adjusted-r-squaredand-predicted-r-squared-to-include-the-correct-number-ofvariables.

[22] L. Breiman, J. H. Friedman, R. Olshen, and C. J. Stone, Classification and Regression Trees, Wadsworth \& Brooks, Monterey, CA, USA, 1984.

[23] T. Therneau, B. Atkinson, and B. Ripley, "rpart: recursive partitioning for classification, regression and survival trees. $\mathrm{R}$ package version 4.1-15," 2019, https://cran.r-project.org/ package $=$ rpart.
[24] K. Hornik, C. Buchta, T. Hothorn, A. Karatzoglou, D. Meyer, and A. Zeileis, Package 'RWeka', 2018.

[25] H. Han, X. Guo, and H. Yu, "Variable selection using mean decrease accuracy and mean decrease gini based on random forest," in Proceedings of the 2016 7th IEEE International Conference on Software Engineering and Service Science (ICSESS), pp. 219-224, IEEE, Beijing, China, August 2016. 